\title{
БОЛЕЗНЬ ВИСОЧНО-НИЖНЕЧЕЛЮСТНОГО СУСТАВА:
} БОЛЕЗНЬ - «ХАМЕЛЕОН»

\section{TEMPOROMANDIBULAR JOINT DISEASE: DISEASE - "CHAMELEON"}

K. Gusenkadieva I. Rasulov

Summary. The problem of diagnostics and treatment of anomalies of the temporomandibular joint, due to its complexity, is becoming more and more interesting. This work describes in detail the characteristic symptomatology of the pathology of the temporomandibular joint, describes possible methods of diagnostic studies, as well as options for therapy with a medical and surgical approach. Much attention is paid to the etiology of abnormalities and the importance of an individual approach, both to the moments of diagnosis and to treatment, is emphasized.

Keywords: temporomandibular joint, diagnosis, treatment.
Гусенкадиева Камила Нажмутдиновна Аспирант, Дагестанский государственный медицинский университет kgusenkadiyeva@bk.ru

Расулов Ибрагим Магомедкамильевич Дочент, Дагестанский государственный медицинский университет solist@mail.ru

Аннотация. Проблема диагностики и лечения аномалий височно - нижнечелюстного сустава в связи с его сложностью приобретает всё большие интерес. В настоящей работе подробно описана характерная симптоматика патологии височно-нижнечелюстного сустава, охарактеризованы возможные способы диагностических исследований, а так же варианты терапии при медикаментозном и хирургическом подходе. Большое внимание уделяется этиологии аномалий и подчёркивается важность индивидуального подхода, как к моментам диагностики, так и к лечению.

Ключевые слова: височно - нижнечелюстной сустав, диагностика, лечение.

ния полости рта при зевании или приеме пищи, до удаления зубов и различных травм [14]. Существуют литературные данные, согласно которым аномалии ВНЧС часто (примерно в половине всех случаев) появляются у пациентов после посещения стоматолога [13]. При этом главным триггером считался либо аспект чрезмерной нагрузки на сам сустав в ходе лечебных манипуляций, либо проявление хронических повреждений, что может быть вызвано изменением положения нижней челюсти при лечении, удалении зубов, которые влекут за собой изменение положения сустава - сжатие суставного диска и изменение его локализации, что в свою очередь увеличивает вероятность вывиха [12].

Очень часто дисфункция ВНЧС часто проявляется в виде щёлканья в суставе, заклинивания рта, боли в лице и ряде других неприятных симптомов. Более того, что очень часто аномалия ВНЧС способна копировать симптоматику других заболеваний или скрываться за ней. Так, например, данного поражения так же характерны не всегда очевидные симптомы: мигрень и головная боль, скрежет зубов, боли в спине и шее, боль в ушах, невралгия тройничного нерва или напряжение челюсти [12]. Самыми первыми указующими сигналами о дисфункции ВНЧС принято считать боли в месте сочленения сустава, что связано с подвижностью нижней челюсти, напряжённостью или стягиванием жеватель- 
ных мышц, появление хруста, щелчков, треска, хлопанья, наличие зигзагообразных движений при открытии/ закрытии рта, припухлость и асимметрию лица, а кроме того неверную слаженность работы при движении суставной головки и суставного диска [4]

Таким образом, смещение «мизерного» сустава и диска способно сильно снизить качество жизни человека: нарушить процессы приёма пищи, нормальной речи и социализации. Именно поэтому и специалисту, и пациенту нужно понимать, что симптомы представляют собой только верхушку айсберга, но могут подсказать верный путь при диагностике и последующей терапии.

Сегодня в качестве диагностики возможных аномалий ВНЧС применяется широкий спектр методик: сбор анамнеза и опрос самого пациента, пальпация и осмотр, методики магнитно - резонансной томографии, и ультразвукового исследования. Следует отметить, что именно комбинированное применение различных способов при диагностике позволяет в кратчайшие сроки распознать аномалию ВНЧС, подобрать советующую схему лечения и немедленно приступить к терапии, что особенно актуально, если клиническая картина аномалии ВНЧС «смазана» чем - либо ещё $[2,3]$.

Как уже было отмечено ранее, чаще всего пациенты жалуются на ряд первоочередных, заметных симптомов - боли, хруст, заклинивание или ограничение в движении нижней челюсти.

Кроме того, в клинической практике чаще всего проводят обследование: изучение степени подвижности нижней челюсти при открытии и закрытии рта с определением амплитуды и симметричности движений нижней челюсти, исследуется характер экскурсии суставных головок, симптоматика нарушения височно - челюстных суставов и состояние жевательных мышц в состоянии покоя и работы. Кроме того, особое внимание уделяется типу прикуса $[2,11]$.

Кроме того, для диагностики и постановления диагноза применяют широкий спектр инструментальных методик.

Одним из них являются лучевые методы диагностики. Самым распространённым и простым методом считается рентгенография, что позволяет просто и наглядно установить состояние костных структур элементов сустава. Однако, данный подход не способен отразить состояние мягких структур внутри сустава, а классические варианты обзорной рентгенографии не способны детально отобразить состояния ряда костных элементов из-за наслоения других структур черепа [4,6]. Поэтому в последние годы актуальность приобретает вариант артрографии, что представляет собой рентгенографическое исследование с введением контрастного вещества в полость сустава. Подобный вариант часто комбинируется с аспектом линейной томографии, что позволяет более детально и дробно изучить аномалии при ВНЧС [7].

Не меньшее распространение получила методика компьютерной томографии. Она позволяет исследовать не только костные аспекты, такие как локализацию суставных головок по отношению друг к другу, форму суставных поверхностей, но и элементы мягких тканей. Однако, для лучшей оценки состояний мягких тканей, целесообразно использовать контрастное вещество [1].

Несколько более прогрессивной методикой считается применение ультразвукового исследования, поскольку помимо состояния твёрдых костных элементов, можно оценить и состояние прилегающих более мягких структур. Согласно имеющимся литературным данным, для лучшей диагностики целесообразно использовать датчики более высокой частоты, а так же вариант трёхмерного ультразвукового исследования [10].

Согласно имеющимся литературным данным при лечении патологий ВНЧС большое внимание уделяется комплексному, мультитаргетному подходу, при котором терапия способна влиять на разные звенья патологического процесса. Так, установлено, что при лечении первоочередное значение имеет снятие боли и спазма мышц, исключение симптомов декомпрессии сустава, восстановление суставного диска, а так же целостности зубных рядов при необходимости и регенерация костной и хрящевой ткани $[1,9]$.

Несмотря на то, что на сегодняшний день существует ряд общих принципов, правил и схем согласно которым и поводится сама терапия, в моментах непосредственно клинической практики должен преобладать индивидуальный подход к каждому пациенту. Так, например, для терапии внутренних нарушений целесообразно применить индивидуальную окклюзионную шину, которые в зависимости от направленности лечения имеют градацию на разобщающие, миорелаксирующие, стабилизирующие и репозиционные шины $[8,13]$.

В последнее время особую актуальность приобрели малоинвазивные методики хирургического вмешательства - артролаваж и артроцентез. Так, вариант артролаважа представляет собой очищение суставной полости посредством промывания её раствором Рингера или физиологическим раствором, что позволяет нивелировать развитие воспалительного процесса, устраняет фиброзные спайки и создаёт оптимальные вариант для верного положения суставного диска при паталогическом изме- 
нении его локализации. Процедура артроцентеза несколько похожа на вариант артролаважа и применяется, как правило, при вывихах и более тяжёлых и длительных аномалиях ВНЧС. Она отличается от предыдущего варианта тем, что введению раствора Рингера предшествует введение местного анестетика, а после него, для восстановления хрящевой ткани, целесообразно вводить хондропротекторные препараты на основе гиалуроновой кислоты, глюкозамина и хондроитина $[2,13]$.

\section{Зак^ючение}

В результате, становится очевидна важность комплексного подхода при лечении симптомов и меха- низмов развития аномалий ВНЧС, а так же коррекции специфики их проявления. Становится очевидно, что важными задачами современного здравоохранения должны стать не только внедрение превентивных мер профилактики и предупреждение развитие подобных нарушений, что особенно актуально ввиду их вероятного хронического характера, но и изучение и изыскание новых, более совершенных методик диагностики патологий ВНЧС. Становится очевидно, что из-за особой сложности строения самой структуры, только благодаря индивидуальному, но в то же время комплексному способу лечения становится возможным полностью нивелировать негативную симптоматику при данном заболевании.

\section{ЛИТЕРАТУРА}

1. Иорданишвили А.К., Сериков А.А., Солдатова Л.Н., Жидких Е.Д., Овчиннков К.А., Николайчук Е.А. Оценка лечения патологии височно - нижнечелюстного сустава на фоне дисплазии соединительной ткани с использованием синдрома психосенсорно - анатомо - функциональной дезадаптации. Курский научно — практичекий естник «Человек и его здоровье». - 2018. —№ 3.

2. Иванов С.Ю. Диагностика и комплексное лечение заболеваний височно — нижнечелюстного сустава. - 2019.

3. Ефанова Н.С. Комплексный подход к диагностике и лечению заболеваний ВНЧС. Международный студенческий вестник. -2016. 一№ 2-С.60.

4. Сангулия С.Г., Зизевский С.А. Комплексная оценка результатов лечения больных с дисфункцией височно - нижнечелюстного сустава. Казанский медицинский журнал. - 2004.- Т. 85.—№ 3.

5. Иорданишвили А., Рыжак Г., Солдатова Л. Диагностика и лечение заболеваний височно — нижнечелюстного сустава у людей пожилого и старческого возраста. Litres, 2021.

6. Aiello G., Metcalf I. (1992). Anaesthetic implications of temporomandibular joint disease. Canadian journal of anaesthesia, 39(6), 610-616.

7. Haskin C.L., Milam S.B., Cameron I.L. (1995). Pathogenesis of degenerative joint disease in the human temporomandibular joint. Critical Reviews in Oral Biology \& Medicine, 6(3), 248-277.

8. Kamelchuk L.S., Major P.W. (1995). Degenerative disease of the temporomandibular joint. Journal of orofacial pain, 9(2).

9. Warmerdam E.P.L., Klein W.R., Van Herpen B.P.J.M. (1997). Infectious temporomandibular joint disease in the horse: computed tomographic diagnosis and treatment of two cases. Veterinary Record, 141(7), 172-174.

10. Joint T. (2012). Temporomandibular Joint. Physical Rehabilitation of the Injured Athlete: Expert Consult-Online and Print, 282.

11. Wolford L.M. (1997). Temporomandibular joint devices: treatment factors and outcomes. Oral Surgery, Oral Medicine, Oral Pathology, Oral Radiology, and Endodontology, 83(1), 143-149.

12. Posselt U. (1971). The temporomandibular joint syndrome and occlusion. The Journal of prosthetic dentistry, 25(4), 432-438.

13. Guarda-Nardini L., Tito R., Staffieri A., Beltrame A. (2002). Treatment of patients with arthrosis of the temporomandibular joint by infiltration of sodium hyaluronate: a preliminary study. European archives of oto-rhino-laryngology, 259(5), 279-284.

14. Güven 0. (2000). A clinical study on temporomandibular joint ankylosis. Auris Nasus Larynx, 27(1), 27-33.

с Гусенкадиева Камила Нажмутдиновна ( kgusenkadiyeva@bk.ru ), Расулов Ибрагим Магомедкамильевич ( solist@mail.ru ). Журнал «Современная наука: актуальные проблемы теории и практики» 